\title{
Air Quality at Your Street - Public Digital Map of Air Quality in Denmark
}

\author{
S.S. Jensen ${ }^{1 \#}$, M. Ketzel' ${ }^{1}$, J. Brandt ${ }^{1}$, T. Becker ${ }^{1}$, M.W. Fuglsang ${ }^{2}$, M. Plejdrup ${ }^{1}$, M. Winther ${ }^{1}$, T. \\ Ellermann ${ }^{1}$, J.H. Christensen ${ }^{1}$, O.-K. Nielsen ${ }^{1}$, and O. Hertel ${ }^{1}$ \\ ${ }^{1}$ Department of Environmental Science, Aarhus University, Frederiksborgvej 399, 4000 Roskilde, \\ Denmark; "Email: ssj@envs.au.dk \\ ${ }^{2}$ Sweco Danmark A/S, Granskoven 8, DK-2600 Glostrup, Denmark
}

\begin{abstract}
A digital map of air quality of annual concentrations of $\mathrm{NO}_{2}, \mathrm{PM}_{2.5}$ and $\mathrm{PM}_{10}$ in 2012 has for the first time been presented on the internet for all 2.4 million addresses in Denmark. The air quality data have been generated on basis of a multi-scale air quality modelling approach, consisting of a suite of chemistry-transport models all developed at Aarhus University and including regional modelling, urban background modelling and street modelling. Information about traffic volumes is based on a newly developed Danish National Passenger Model, and national travel speed data have been obtained from a recent dataset based on GPS readings of vehicles. Air quality model results are validated by comparisons with measurements obtained from the fixed site monitoring stations under the Danish Air Quality Monitoring Programme. In general, the comparison indicates that predicted street concentrations give a fairly accurate picture of air quality at addresses, its geographic variation and the relative differences between areas. The target group for the air quality map is the general Danish population and aiming for providing information and awareness about air quality. Other target groups include local and national authorities and consultants whom may use the information as a screening tool for air quality assessment. The user interface of the air quality map is based on WebGIS and is available in Danish and English at http://luftenpaadinvej.au.dk.
\end{abstract}

Key words: air quality, map, model, validation, traffic, WebGIS.

\section{Introduction}

Road traffic is one of the main contributors to human exposure to air pollution in Europe. In many of the European countries, including Denmark, health effects related to air pollution is an important concern to the public. Furthermore, a number of NGOs with focus on environmental pressures have been formed with the aim to influence environmental policy towards sustainable development. Citizens seek information about air pollution when they are deciding for where to buy a house or an apartment, or when they are concerned about the air pollution level where their children go to school etc. This has been the main driver for developing an information system called 'Air Quality at Your Street", where the Danish population can access information about air quality at any address in the country.

\section{Methodology}

The air quality is calculated with a model system consisting of a regional long-range transport model (DEHM), an urban background model (UBM) and a street pollution model
(OSPM®) with required emissions and meteorological data etc.:

(a) DEHM in combination with UBM calculates background concentration. DEHM ${ }^{[3],[4],[6]}$ is a three dimensional, offline, large-scale, Eulerian, nested grid, atmospheric chemistry transport model developed for studying long-range transport of air pollution on the Northern Hemisphere, and it predicts regional background concentrations. UBM ${ }^{[1],[6]}$ is a multiple source model that applies a Gaussian approach for horizontal dispersion and a linear approach for vertical dispersion up to the boundary layer.

(b) OSPM $\AA^{[2],[9]}$ calculates street concentrations where urban background concentrations from DEHM/UBM are included. OSPM® combines a plume model for the direct contribution from the traffic source and a box model for the recirculation of pollution inside the street environment.

(c) AirGIS ${ }^{[7],[8],[10]}$ is used to generate input about traffic and street geometry for OSPM®. This is done for all addresses along the road 
network of the Danish National Passenger Model $^{[13]}$ (LTM) from Transport DTU. Data for travel speeds are based on GPS data from SpeedMap from the Danish road Directorate (http://speedmap.dk/portal). Street geometry for a given address point is calculated based on the road network with traffic data and building footprints with building heights.

(d) Emission data for Denmark have a high spatial resolution of $1 \mathrm{~km} \times 1 \mathrm{~km}$ based on a model for the geographic distribution of national emissions (SPREAD ${ }^{[11],[12]}$ ), and for Europe and the rest of the Northern hemisphere a number of international emission inventories is used.

\section{WebGIS user interface}

Parts of the user interface are illustrated below. Background concentrations with a geographic resolution of $1 \mathrm{~km} \times 1 \mathrm{~km}$ are shown for $\mathrm{NO}_{2}$ in Fig. 1.

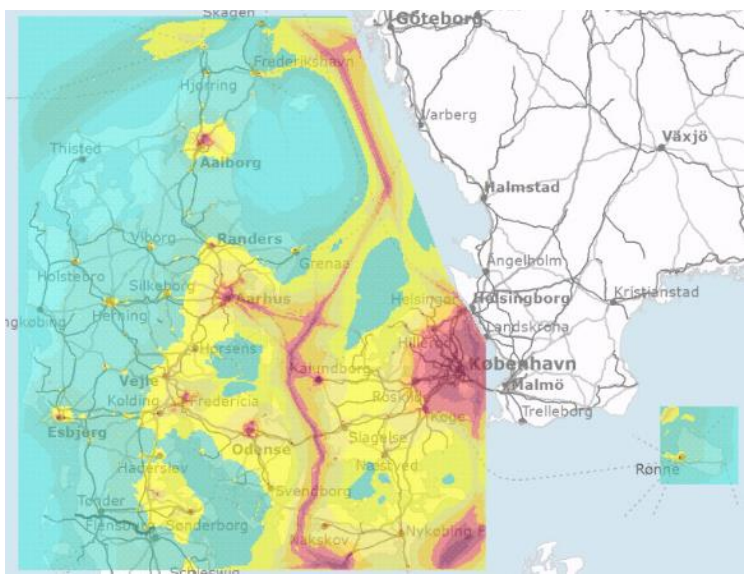

Fig 1. Map of $\mathrm{NO}_{2}$ background concentrations for the entire country.

An example of a zoom in on the Greater Copenhagen Area is shown in Fig.2.

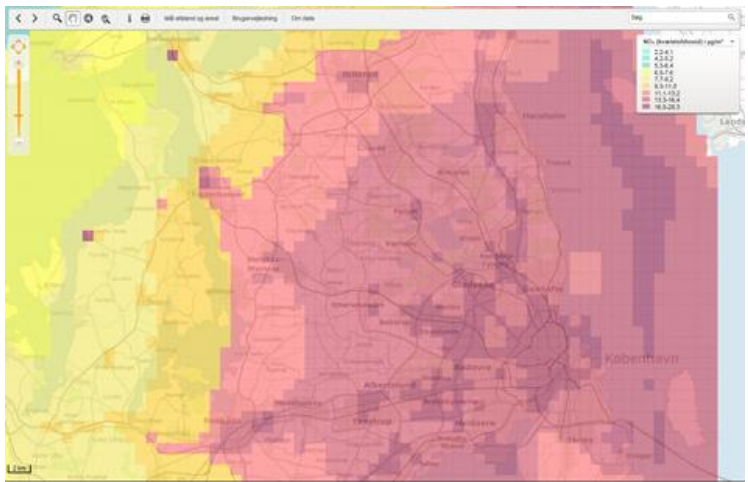

Fig 2. A zoom in on the Greater Copenhagen Area for $\mathrm{NO}_{2}$ background concentrations where the geographic resolution of $1 \mathrm{~km} \times 1 \mathrm{~km}$ is clearly visible.

It is also possible to search for a specific address by typing street name, house number and city. In Fig. 3 an example of an address search is shown.

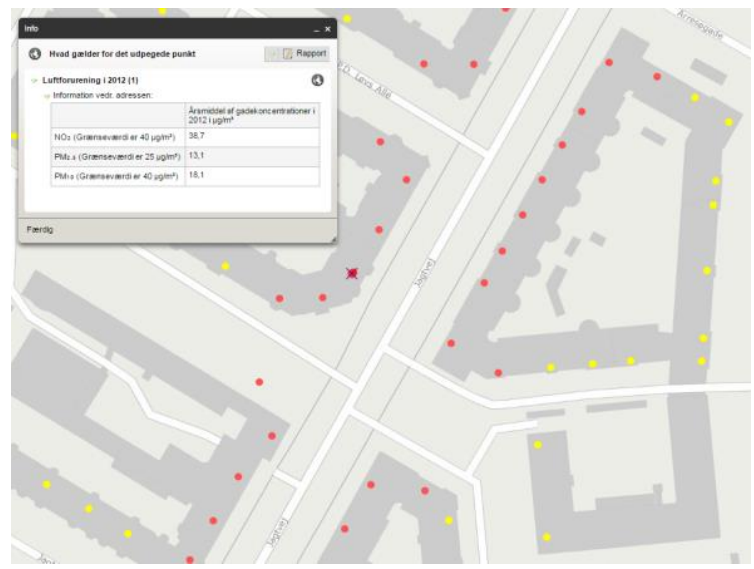

Fig 3.An infobox showing air quality levels of $\mathrm{NO}_{2}$, $P M_{2.5}$ and $P M_{10}$ for a specific address. Limit values are also given. Street concentrations are shown as colored dots according to air quality levels on top of address points.

The map scale will automatically shift from showing background concentrations to showing street concentrations at a certain zoom level when the user zoom in. In Fig. 3 street concentrations are visualized.

The website includes popular information about the purpose of the map, what it shows, how air quality is calculated, data uncertainties and limitations, air quality limit values, and how to interpret health risk of air pollution. The user interface is in Danish and English.

\section{Background concentrations}

The geographical distribution of modelled background concentrations with DEHM/UBM is shown in Fig. 4, 5 and 6 for $\mathrm{NO}_{2}, \mathrm{PM}_{2.5}$ and $\mathrm{PM}_{10}$, respectively.

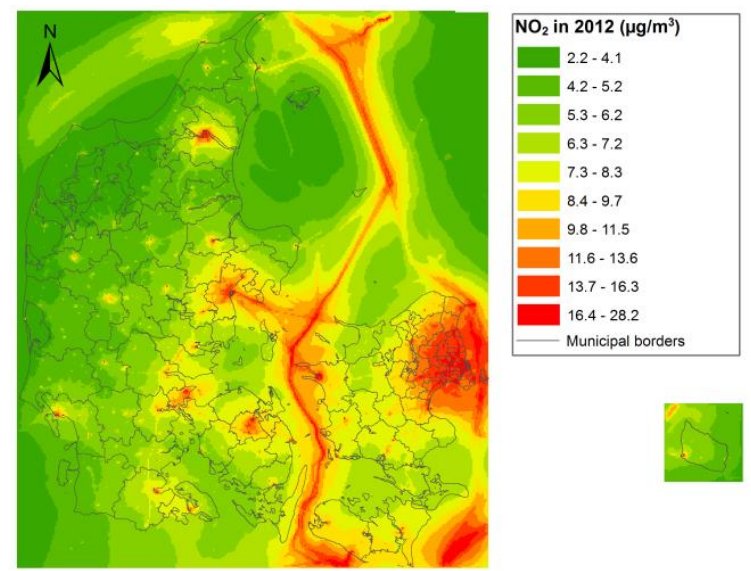

Fig. 4. Annual mean $\mathrm{NO}_{2}$ background concentrations in 2012 based on UBM calculations with regional input from DEHM. 


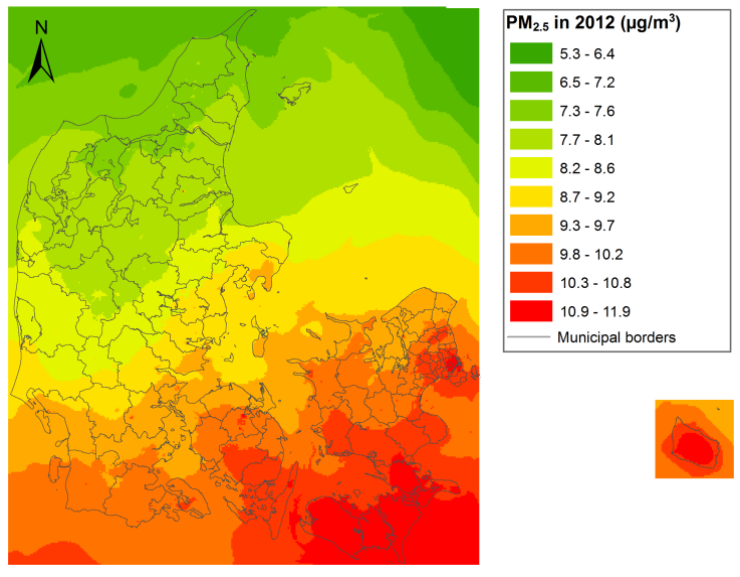

Fig.5. Annual mean $P M_{2.5}$ background concentrations in 2012 based on UBM calculations with regional input from $D E H M$.

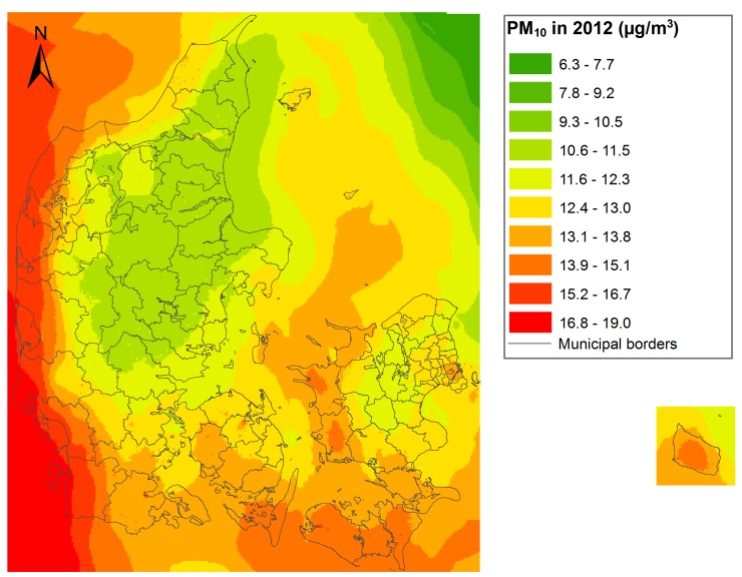

Fig. 6. Annual mean $P M_{10}$ background concentrations in 2012 based on UBM calculations with regional input from DEHM.

The geographic distribution of $\mathrm{NO}_{2}$ background concentrations over land and marine areas shows a clear signal from local sources (see Fig. 4). This is visible especially for contributions from road traffic as the larger cities and major transport corridors have the highest concentrations. Over marine areas the international ship traffic passing through Danish marine areas are clearly shown with high concentrations. The latter leads furthermore to elevated concentrations at nearby coastal land areas.

The geographic distribution of $\mathrm{PM}_{2.5}$ background concentrations has a different pattern than $\mathrm{NO}_{2}$, since there is a clear gradient from south to north (see Fig. 5). The reason is that $\mathrm{PM}_{2.5}$ concentrations are dominated by regional background pollution as a result mainly of long-rang transport from Western and Central Europe.

The geographic distribution of $\mathrm{PM}_{10}$ background concentrations is clearly influenced by the contribution of sea salt (see Fig. 6). This is seen in the high $\mathrm{PM}_{10}$ concentrations at the west coast of Jutland (western part of the country) and to a lesser extent on the western coast areas of the main islands in the inner waters. The latter is due to the predominant westerly winds in Denmark. The same gradient from south to north as for $\mathrm{PM}_{2.5}$ is also visible for $\mathrm{PM}_{10}$ as $\mathrm{PM}_{2.5}$ is part of $\mathrm{PM}_{10}$.

\section{Street concentrations}

The geographical distribution of modelled $\mathrm{NO}_{2}$ street concentrations over land areas calculated with $\mathrm{DEHM} / \mathrm{UBM} / \mathrm{OSPM}{ }^{\circledR}$ is shown in Fig. 7. The calculation points are represented by all address points located along the road network of the Danish Passenger Model and include about 201,000 calculation points. Street concentrations at the other 2.2 million addresses are equal to urban background concentrations as traffic levels are insignificant e.g. on residential streets.

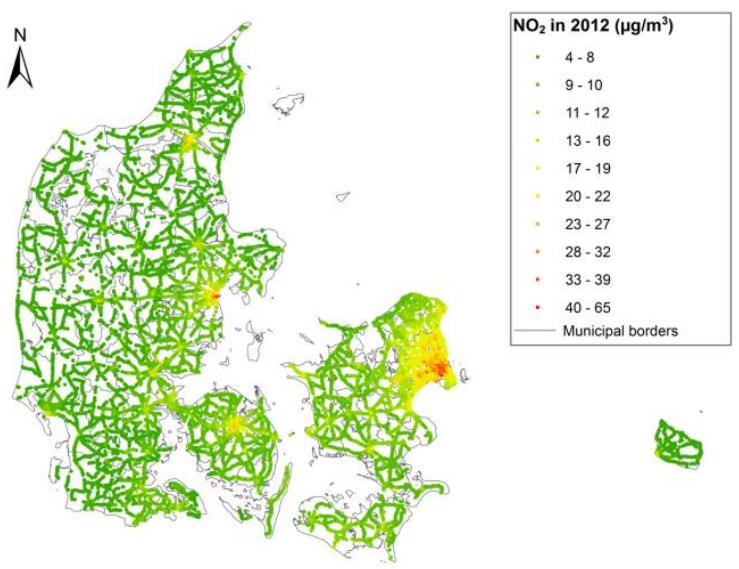

Fig. 7. Annual mean $\mathrm{NO}_{2}$ street concentrations along the road network of the Danish Passenger Model in 2012.

Street concentrations for $\mathrm{NO}_{2}$ show the highest concentrations in the larger cities due to the contribution from road transport (Fig. 7) but also as a result of elevated urban background concentrations (see Fig. 4).

$\mathrm{NO}_{2}$ is given as an example, since Denmark is facing a problem with exceedance of the limit value for annual mean concentrations of $\mathrm{NO}_{2}$ at a busy street station in Copenhagen ${ }^{[5]}$.

\section{Model system validation}

A comparison of model calculations and measurements for 2012 based on the fixed background and street measurement stations under the Danish Air Quality Monitoring Programme ${ }^{[5]}$ was performed.

The comparison with the five street measurement stations shows that calculations 
are within - $27 \%$ to $12 \%$ for $\mathrm{NO}_{2}$, and $-7 \%$ to $23 \%$ for $\mathrm{PM}_{2.5}$ and $-36 \%$ to $-22 \%$ for $\mathrm{PM}_{10}$. These measurement stations are in the four largest cities in Denmark: Copenhagen, Aarhus, Odense and Aalborg. The difference between the model calculations and measurements illustrates the expected uncertainty of calculations for busy streets. Detailed analysis shows that in some cases the calculations can be misleading because the input data are not representative for the local conditions.

\section{Conclusion}

For the first time in Denmark the annual air quality concentrations of $\mathrm{NO}_{2}, \mathrm{PM}_{2.5}$ and $\mathrm{PM}_{10}$ in 2012 have been modelled for all about 2.4 million addresses in Denmark based on a multiscale integrated air quality modelling approach and presented on a public website based on WebGIS.

\section{Acknowledgements}

This work was supported by Danish Centre for Environment and Energy (DCE) under Aarhus University, Denmark. The Technical University of Denmark, Transport DTU) provided a national road network (navteq) with modelled traffic data for 2010 from the Danish National Passenger Model. The Danish Road Directorate provided travel speed data for 2012 (SpeedMap) for the national road network (navteq). Also courtesy to the Danish Geodata Agency for making national address data, national building foot prints data and national elevation model data open source data.

\section{References}

[1] Berkowicz, R., (2000a): A simple model for urban background pollution. Environmental Monitoring and Assessment 65 (1/2), 259-267.

[2] Berkowicz, R., (2000b): OSPM - A parameterised street pollution model. Environmental Monitoring and Assessment 65 (1/2), 323-331.

[3] Brandt, J., Silver, J.D., Frohn, L., Geels, C., Gross, A., Hansen, A.B., Hansen, K.M., Hedegaard, G.B, Skjøth, C. A., Villadsen, H., Zare, A., Christensen, J., H., (2012): An integrated model study for Europe and North America using the Danish Eulerian Hemispheric Model with focus on intercontinental transport. Atmospheric Environment, Volume 53, June 2012, pp, 156-176, doi:10,1016/j,atmosenv,2012,01,011.

[4] Christensen, J.H. 1997: The Danish Eulerian Hemispheric Model - a three-dimensional air pollution model used for the Arctic. Atmospheric Environment, 31, 4169-4191.

[5] Ellermann, T., Nøjgaard, J.K., Nordstrøm, C., Brandt, J., Christensen, J., Ketzel, M., Jansen,
S., Massling, A. \& Jensen, S.S. (2013): The Danish Air Quality Monitoring Programme. Annual Summary for 2012. Scientific Report from DCE - Danish Centre for Environment and Energy. No. 67. 62 pp. http://dce2.au.dk/pub/SR67.pdf

[6] Frohn, L. M., Christensen, J.H., Brandt, J. and Hertel, O., 2001. Development of a high resolution integrated nested model for studying air pollution in Denmark. Physics and Chemistry of the Earth (B), 26(10), 769-774. http://dx.doi.org:10.1016/S1464-1909(01)00084-3

[7] Jensen, S.S., Berkowicz, R., Hansen, H.S., Hertel, O., (2001): A Danish decision-support GIS tool for management of urban air quality and human exposures. Transportation Research Part D-Transport and Environment 6, 229-241.

[8] Jensen, S.S., Larson, T., Deepti, K.C., Kaufman, J.D. (2009): Modeling Traffic Air pollution in Street Canyons in New York City for Intra-urban Exposure Assessment in the US Multi-Ethnic Study of Atherosclerosis. Atmospheric Environment 43 (2009) 4544-4556. http://dx.doi.org/10.1016/j.atmosenv.2009.06.042.

[9] Kakosimos, K.E., Hertel O., Ketzel M., Berkowicz R. (2011): Operational Street Pollution Model (OSPM) - a review of performed validation studies, and future prospects, Environmental Chemistry, 7, 485-503.(doi-Link).

[10] Ketzel, M., Berkowicz, R., Hvidberg, H., Jensen, S.S., Raaschou-Nielsen, O. (2011): Evaluation of AirGIS - A GIS-Based Air Pollution And Human Exposure Modelling System. Int. J. of Environment and Pollution. Vol. 47, Nos. 1/2/3/4, 2011. DOI: 10.1504/IJEP.2011.047337.

[11] Nielsen O.-K., Winther, M., Mikkelsen, M.H., Hoffmann, L., Nielsen, M., Gyldenkærne, S., Fauser, P., Plejdrup, M.S., Albrektsen, R., Hjelgaard, K., Bruun, H.G. (2013). Annual Danish Informative Inventory Report to UNECE: Emission inventories from the base year of the protocols to year 2011. Aarhus University, DCE Danish Centre for Environment and Energy. 699 s. (Scientific Report from DCE - Danish Centre for Environment and Energy; Nr. 53).

[12] Plejdrup, M.S. \& Gyldenkærne, S. (2011): Spatial distribution of emissions to air - the SPREAD model. National Environmental Research Institute, Aarhus University, Denmark, 72 pp. NERI, Technical Report no. FR823, http://www.dmu.dk/Pub/FR823.pdfhttp://www.dm u.dk/Pub/FR823.pdf.

[13] Rich, J., Hansen, C. H. (2015): The Danish National Passenger Model. Working Paper. December 2015. DOI:

10.13140/RG.2.1.3661.7040. European Journal of Transport and Infrastructure Research.

[14] EEA (2015): Air quality in Europe - 2015 report. EEA Report No. 5/2015. European Environment Agency. 57 pp. ISBN 978-92-9213-702-1 doi:10.2800/62459. 